Faculty, Energy, Environment \& Resource Sustainability

\title{
Assessment of Organic and Inorganic Pollutants Along The Qatari Coast
}

${ }^{1,2}$ Noora AlJathelah AlShamary, ${ }^{2}$ Simon Hutchinson, ${ }^{2}$ Debapriya Mondal

${ }^{1}$ Qatar University, Environmental Science Center, P.O. Box 2713, Doha, Qatar

${ }^{2}$ University of Salford Manchester, School of Environment \& Life Studies, Salford, M5 4WT, United Kingdom

\begin{abstract}
Qatar sits in the middle of the world's most important hydrocarbon producing areas where significant regional refining activity and shipping traffic take place. In addition significant local coastline development, prominently along the eastern coast, has taken place over recent decades. Protecting Qatar's marine ecosystems from the adverse effects of environmental contaminants is a core component of the Environmental Development pillar within the National Vision 2030. However, a limited number of studies have investigated contaminant concentrations in the coasta environment $Q$ atar. The accumulation of contaminats in aquatic aquatic effect for marine organisms and human health

This study aims to determine environmental contamination in Qatar's coastal environment by measuring organic and inorganic contaminants, along with physiochemical parameters, at four sites located on the contrasting east and west coast of the country. The Pearl Oyster Pinctada radiata, which is considered an iconic organism in Qatar, was used to determine a baseline of contaminants in an aquatic organism. Surface seawater, surface sediment and oysters were collected four times over two years in different seasons from the four sites. In-situ parameters years in dicters (temperature, $\mathrm{pH}$, and salinity), and abiotic parameters (TOC and grain sizes) were measured for seawater and sediment. Organic (TPHs, PAHs)
and inorganic contaminants (trace metals including: $\mathrm{Cd}, \mathrm{Cu}, \mathrm{Cr}, \mathrm{Ni}, \mathrm{Pb}$ and and inorganic contaminants (trace metal
$\mathrm{Zn}, \mathrm{T}-\mathrm{Hg}$ ) were measured in all samples

$\mathrm{n}$, T-Hg) were measured in all samples .
Overall, Al Wakra (higher in boat traffic and fueling activities) on the east coast reported the highest levels of contaminants. High PAHs were observed in oyster tissues, while high $\mathrm{Pb}$ was noted in seawater and high Zn was observed in sediment and oyster. Benzo (a) pyrene was the highes compound detected in oyster. However, high TPHs webre also noted in oyster tissues from Simaisma. At Al Khor, also on the east coast, high level of TPHs were recorded in seawater, while high PAHs and TOC observed in surace sedime which had a reltively higher clay a dill corved in surface sedis. (he coast), the sole sample site on the west coast, showed the highest level of TOC in
seawater and sediment, highest Ni in seawater and highest total mercury in oyster.

Our results, in general, report lower levels in seawater and sedimen compared to other studies in the region and more widely; however, in oysters most of the contaminants are higher when compared to international guideline values. These higher levels indicate the potential for these filter feeding organisms to absorb contaminants into their tissues from the environment that surrounds them. Additionally, bioaccir tissues from the enc investigation to understand the presence and distribution of organic and inorganic contaminants in Qatar's rapidly changing coastal environment. It indicates the usefulness of applying an holistic view to environmenta monitoring including the use of biomonitoring.
\end{abstract}

\section{Aim of the Study}

The aim of this study is to determine the environmental contamination in Qatar's coastal environment by measuring organic and inorganic contaminants using pearl oyster as the indicator study organism for contaminants level in an aquatic environment. The specific objectives are to quantify the levels of organic and inorganic contaminants in abiotic matrices and biotic tissues of $\mathrm{P}$. radiata, to determine the relationship between organic and inorganic contaminants within the matrices of sediments and oyster tissues and to assess the current status of organic and inorganic contaminants levels in Qatar coastal environment by comparing it with the National and International standards.

\section{Sampling and Study Area}

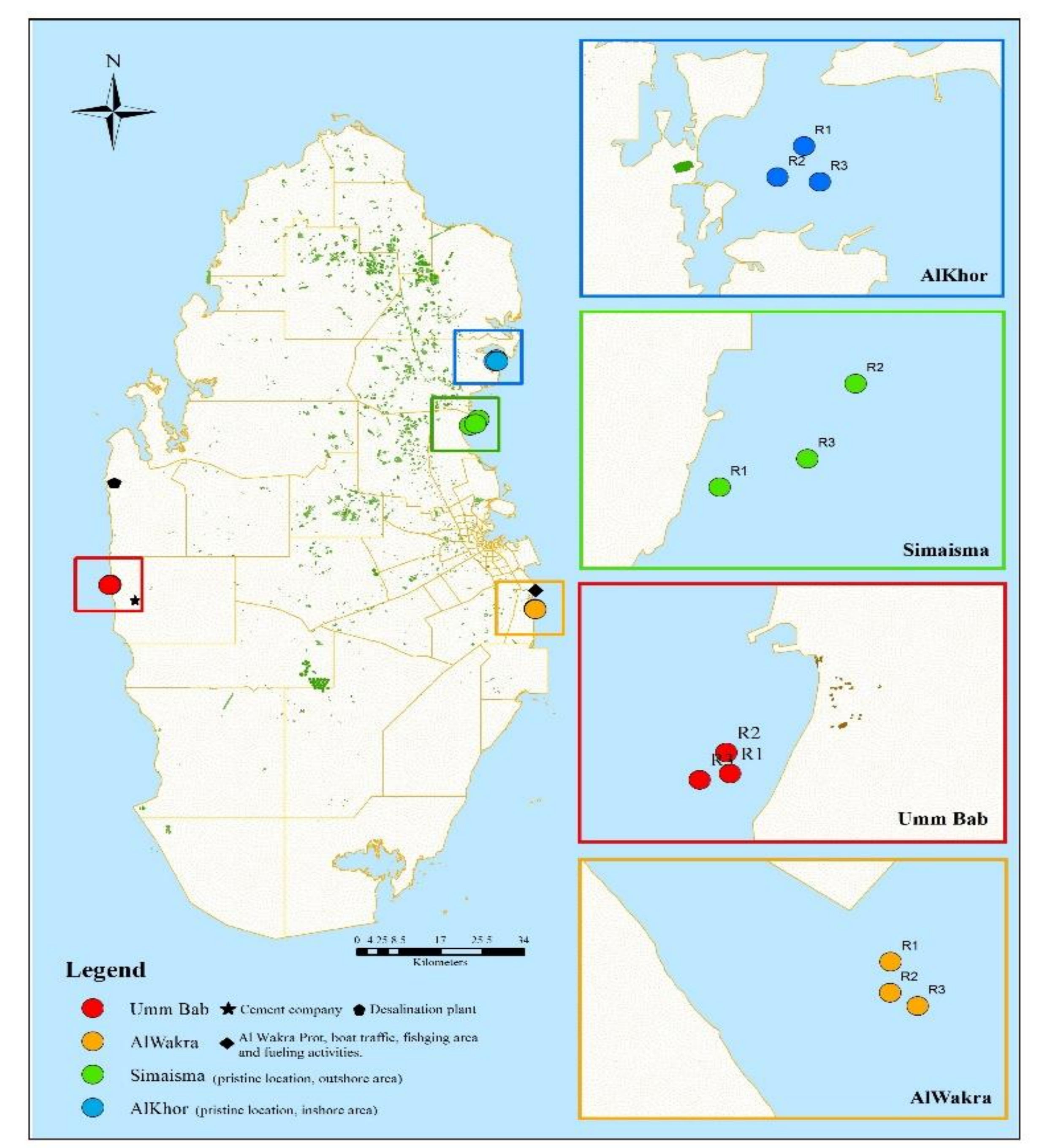

\section{Samples Analysis}

\section{- Analysis of TOC}

TOC content in marine sediment samples was measured indirectly by analyzing total carbon (TC) and total inorganic carbon (TIC) using (PrimacsSNC100 - SKALAR instrument). Peak area results for TC and TIC obtained from the instrument were used in the standard calibration curve equation to calculate $\%$ TC and \% TIC in sediment. The \% TOC was determined by the following formula: $\%$ TOC = $\%$ TC - $\%$ TIC

- Analysis of particle size

About 2 to $5 \mathrm{~g}$ (depending on the sediment texture) of fresh wet marine sediment samples were sieved through $2 \mathrm{~mm}$ mesh size sieve and analyzed for size distribution by Mastersizer 3000, Malvern analyzer.

- Analysis of TPHs and PAHs

The TPHs was analyzed using an Agilent 6890N Network Gas Chromatograph (GC) with Flame Ionization Detector (FID), and for the PAHs analysis Agilent 7890B gas chromatograph coupled to a 5975C triple-axis mass spectrometer (GCMS) was used.

- Analysis of trace metals

The trace metals including $\mathrm{Cd}, \mathrm{Cr}, \mathrm{Cu}, \mathrm{Ni}, \mathrm{Pb}$ and $\mathrm{Zn}$ were analyzed in seawater, sediment and oyster tissues samples using ICP-OES (Inductively coupled plasma - optical emission spectrometry) (Perkin-Elmer, Optima 7300 DV model).

\section{- Analysis of T-Hg}

For total mercury, samples are analysed using the Automatic Mercury Analyzer AULA-254 ASD. Samples introduced into a mixer with stannous chloride solution (tin (II)), then to a reaction cell, and argon gas carries the elemental mercury from the sample to the detector which measures the mercury concentration.

\section{Results and Discussion}


- The highest TPHs and PAHs levels in surface sediment were recorded in samples collected from Al Khor where the sediment TOC was found and the sediment texture comprised at greater proportion of finer sediment (e.g., $1.7 \%$ clay, $22 \%$ silt).

Both the level of TPHs and PAHs in surface sediment were in low range compared to other studies around the world.

- Al Wakra sediment samples showed the highest levels of $\mathrm{Cr}$ and $\mathrm{Zn}$ compared with the other three sites $(14.45 \mu \mathrm{g} / \mathrm{g}$ and $14.92 \mu \mathrm{g} / \mathrm{g}$ respectively).

Oyster tissues

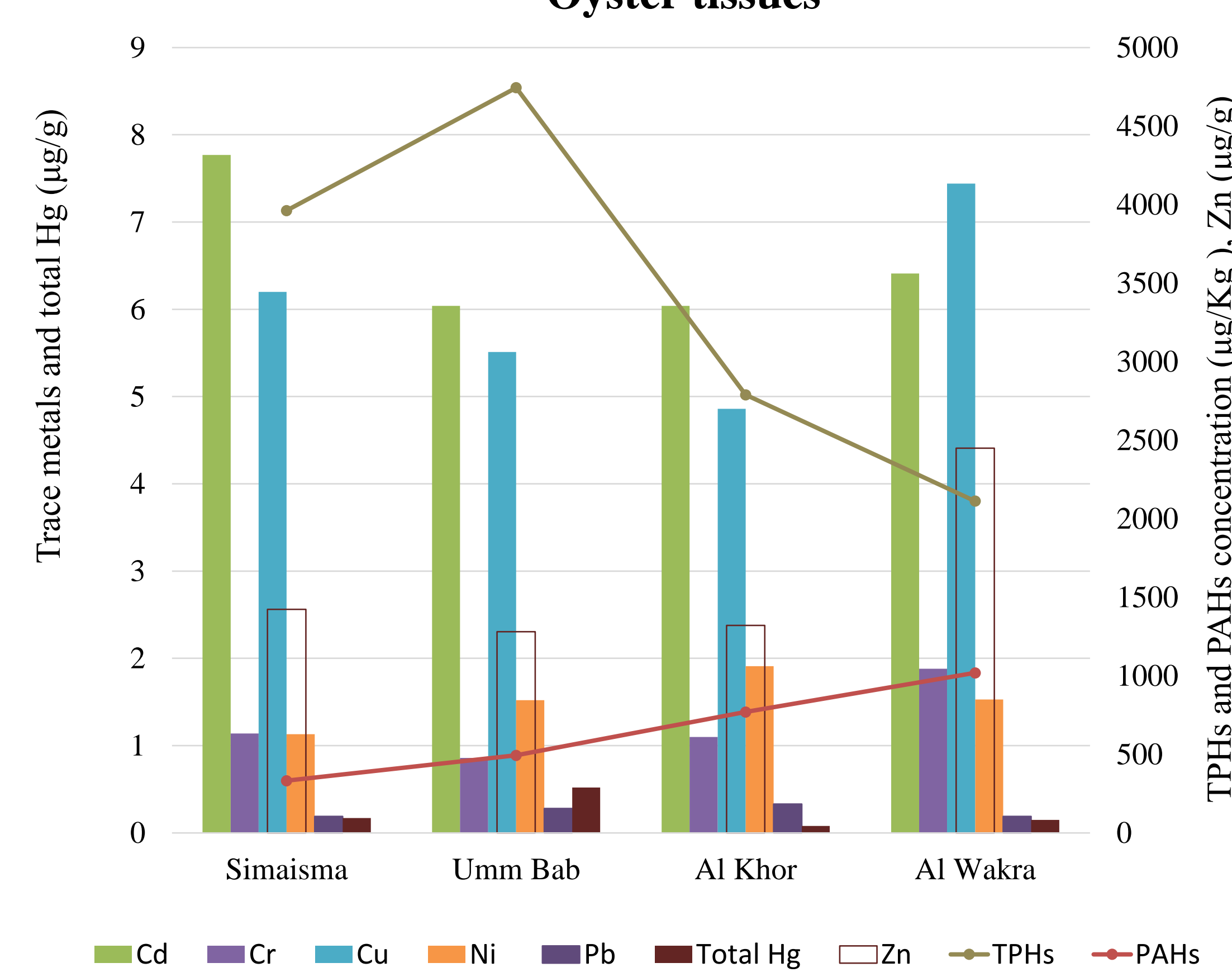

- The TPHs concentration range reported in P.radiata tissues in this study was lower than previous local studies, while PAHs levels were higher than the previous local study and levels reported in other countries.

- Benzo (a) pyrene, which grouped in the first cluster as the most carcinogenic PAHs compound, was the highest compound detected in oyster tissues.

- The trace metals in the pearl oyster samples showed the following rank order of accumulation: $\mathrm{Zn}>\mathrm{Cd}>\mathrm{Cu}>$ $\mathrm{Ni}>\mathrm{Cr}>\mathrm{Pb}$.

- The level of zinc recorded in pearl oyster tissues in this study was extremely higher than any recorded studies around the world.

\section{Conclusion}

Even though levels of organic and inorganic contaminants recorded in this study in surface seawater and coastal sediment samples were low and below the international guideline limits, high levels detected in pearl oyster tissues may give an indication of sources of contamination in Qatar coastline. Since coastal sediments consider being a very useful tool to evaluate contamination, recording of low concentrations indicates non-anthropogenic impact (Memet, 2011). Thus, the estimation that high levels detected in oysters may be duo to non-point sources that occur in the four studied sites at specific time or duo to regional marine activities surrounding the coastline of Qatar. 